\title{
Sex and nest type influence avian blood parasite prevalence in a high-elevation bird community
}

Marina D. Rodriguez ${ }^{1 *}$ (⿺辶) Paul F. Doherty ${ }^{1}$, Antoinette J. Piaggio ${ }^{2}$ and Kathryn P. Huyvaert ${ }^{1}$

\begin{abstract}
Background: The prevalence of avian haemosporidian parasites and the factors influencing infection in the Colorado Rocky Mountains are largely unknown. With climate change expected to promote the expansion of vector and avian blood parasite distributions, baseline knowledge and continued monitoring of the prevalence and diversity of these parasites is needed.

Methods: Using an occupancy modeling framework, we conducted a survey of haemosporidian parasite species infecting an avian community in the Colorado Rocky Mountains in order to estimate the prevalence and diversity of blood parasites and to investigate species-level and individual-level characteristics that may influence infection.

Results: We estimated the prevalence and diversity of avian Haemosporidia across 24 bird species, detecting 39 parasite haplotypes. We found that open-cup nesters have higher Haemoproteus prevalence than cavity or ground nesters. Additionally, we found that male Ruby-crowned Kinglets, White-crowned Sparrows, and Wilson's Warblers have higher Haemoproteus prevalence compared to other host species. Plasmodium prevalence was relatively low $(5 \%)$, consistent with the idea that competent vectors may be rare at high altitudes.
\end{abstract}

Conclusions: Our study presents baseline knowledge of haemosporidian parasite presence, prevalence, and diversity among avian species in the Colorado Rocky Mountains and adds to our knowledge of host-parasite relationships of blood parasites and their avian hosts.

Keywords: Haemosporidia, Haemoproteus, Plasmodium, Occupancy modeling

\section{Background}

Parasitism is an important driver of ecological and evolutionary processes $[1,2]$ as parasites may regulate host population size, e.g., Hochachka and Dhondt [3], affect species interactions, e.g., Ricklefs [4], and create selection pressures in wild populations, e.g., Laine [5]. Compounding effects of parasites with other factors such as climate change, competition with invasive species, habitat loss, or harsh environmental conditions can also drive

*Correspondence: mdrod@colostate.edu

1 Department of Fish, Wildlife and Conservation Biology, Colorado State University, Fort Collins, Colorado, USA

Full list of author information is available at the end of the article populations to low numbers, predisposing them to local or global extinction [6-9].

Haemosporida (Phylum: Apicomplexa) are protozoan parasites that infect the blood cells of vertebrates and are transmitted by dipteran vectors [10]. These blood parasites-haemosporidian parasites-are distributed worldwide and infect a number of vertebrates, including mammals [11], reptiles [12], and birds [10]. Blood parasites go through sexual reproduction in dipteran vectors and are transmitted to vertebrate hosts during vectors' blood meals [10]. Once in a competent host, the parasite undergoes asexual reproduction and the infected host becomes a reservoir, carrying developed gametocytes within its red blood cells [10]. 
Among vertebrates, birds are hosts to the highest diversity of haemosporidian parasites, with records of birds being infected with over 200 morphologically distinct haemosporidian parasite species $[10,13,14]$ and over 3000 unique haplotypes [13]. The three parasite genera that infect birds include Haemoproteus, Plasmodium, and Leucocytozoon [10 and 15]. Negative effects of infection can be due to changes in host behavior [16] or to severe physiological responses, resulting in high mortality rates during the acute phase of infection [17, 18]. Avian hosts can also suffer declines in reproductive success $[19,20]$ and reduced lifespan when enduring chronic infections [21]. Within species, factors such as age, sex, immune status, and degree of exposure may also contribute to variation in host susceptibility and mortality [15].

Spatial and temporal dynamics of avian haemosporidian parasite occurrence are governed by environmental, ecological, and demographic characteristics [22-25]. In temperate environments, seasonality has a strong influence on the survival and development of both parasites and insect vectors, as mosquitoes emerge during the spring and are active until the end of the summer [26]. This increase in parasites and vectors coincides with the breeding season for most avian species, when resource allocation is diverted to reproduction instead of immune function $[27,28]$. Our study took place during the breeding season, allowing us to survey avian blood parasites at a time when infection frequency is expected to be highest.

The intensity and seasonality of haemosporidian parasite transmission tends to vary by elevation [29]. Negative correlations between elevation and abundance of mosquitos, the main vectors of avian blood parasites, have been found in many systems including the mountains in Colorado's Front Range [30, 31], where our study site is located. Many parasites have elevation limits because of the constraints of lower ambient temperatures encountered at higher elevations, though distributions are expanding with climate change, as the transmission of most vector-borne parasites may be enhanced by higher ambient temperatures, e.g. Samuel et al. [32], La Pointe et al. [33]. Changes in environmental conditions for vectors, such as an increase in mean air temperature and declining precipitation, support the expansion of haemosporidian parasites into habitats where lower temperatures previously limited transmission [34, 35]. For example, Culex tarsalis and C. pipiens are important vectors of Plasmodium parasites at lower elevations in northeastern Colorado, but the low abundance of these species at higher elevations may mean that Plasmodium is not yet established in areas such as Rocky Mountain National Park [36]. However, little research has been done on the distribution of haemosporidian parasites in Colorado, especially in high-elevation communities like those in the Colorado Rockies.

Across species, factors such as nest type and migration strategy may explain variation in host susceptibility. Although differences in parasite prevalence across nest types is not always found [37-39], open-cup nesting has been linked to higher blood parasite prevalence in numerous studies due to higher vector exposure for incubating individuals compared to cavity- or groundnesting birds [40-44]. Migration has important implications for the emergence and spread of infectious disease-causing parasites due to long-distance movements and exposure to diverse habitats of infected hosts. Establishment of parasites and expansion of their ranges may take place through migration of host species, as parasites are able to survive at higher elevations as environmental conditions become more suitable for parasites and vectors [45]. Migratory birds can harbor high-intensity infections and are host to biologically diverse haemosporidian parasite species [4], allowing them to act as a source of infection to non-migratory birds who may be more susceptible to blood parasites due to lack of previous exposure at higher elevations [46, 47]. With the potential for migratory birds to spread avian blood parasites to new areas, and a warming climate allowing for the spread of blood parasites into new environments, parasite surveillance is needed in bird communities, even those previously thought to be in areas with low parasite prevalence.

Parasite surveys can serve as early indicators of disease outbreaks that could affect the health of avian populations. The study of blood parasites requires knowledge of baseline levels of haemosporidian parasite infection in target host populations to aid in the detection of temporal shifts of parasite diversity to evaluate changes in the prevalence of infection. Using an occupancy approach, we conducted multiple screenings for blood parasites per host in order to better estimate the detection probability of haemosporidian parasites within host species [48, 49]. Occupancy modeling approaches are useful in wildlife disease ecology because they acknowledge that uncertainty, such as false-negative results, exists when using imperfect diagnostic tests $[50,51]$. Variation in detection among multiple screenings of the same blood sample supports the need to use an occupancy modeling framework in order to take detection probability into account in wildlife disease studies [49].

The objectives of our study were (1) to obtain baseline prevalence and diversity estimates for an avian community in the Colorado Front Range Rocky Mountains, where avian parasite surveys have not taken place, and (2) to test differences in prevalence and diversity for various 
individual and species characteristics. Our hypotheses related to the second objective regarding specific host and environmental predictor variables are presented in Table 1.

\section{Methods \\ Study system}

Our study area was located at the Colorado State University Mountain Campus in Larimer County, Colorado, USA (N40.5611, W105.5978), within a mountain valley at an elevation of $2750 \mathrm{~m}$. The valley is a breeding site for numerous bird species, and no prior research on avian blood parasites has been conducted there to our knowledge.

\section{Data collection}

We collected data during the summers of 2017 and 2018. The field portion of our study began in early June, when birds begin breeding, and continued through the end of the breeding season, around mid-August. We captured birds using mist nets set in sites with high passerine activity. Netting sites were in riparian, forested, and edge habitats. Song playbacks were used to attract birds to nets, providing larger sample sizes to facilitate comparisons of parasite prevalence across host species.

Captured birds were identified at the species level and banded. Sex and age were determined when possible based on guidelines from Pyle [52], morphological measurements were taken (tarsus length $(\mathrm{mm})$, wing chord $(\mathrm{mm})$, mass $(\mathrm{g})$ ), and $10-20 \mu \mathrm{l}$ of blood was collected by brachial venipuncture and stored on Nobuto Blood Filter Strips for later DNA extraction. All birds were handled and sampled under a federal bird banding permit from the US Geological Survey (USGS) Bird Banding Laboratory and in accordance with approved guidelines of the Institutional Animal Care and Use Committee of Colorado State University (Protocol 17-7309A).

\section{DNA extraction, PCR amplification, and sequencing}

We assessed haemosporidian parasite infection prevalence and parasite diversity using molecular techniques. We took a $2 \mathrm{~mm}$ hole punch of blood-soaked Nobuto blood filter strip (with $\sim 15 \mu \mathrm{L}$ of blood) for each bird and extracted DNA using the DNeasy 96 Blood \& Tissue Kit (QIAGEN, Valencia, CA), following the manufacturer's dried blood spot protocol. We stored extracted DNA at $-20{ }^{\circ} \mathrm{C}$ prior to screening. We screened an aliquot of DNA for parasite presence using a nested polymerase chain reaction (PCR) protocol to amplify a segment of mitochondrial DNA (mtDNA) from the cytochrome $b$ gene as outlined in Hellgren et al. [53]. Primers HaemNF1 and HaemNR3 were used to amplify an initial 617-bp segment of mtDNA from species of haemosporidian parasites. The conditions for this PCR were as follows: 30 seconds at $94{ }^{\circ} \mathrm{C}, 30$ seconds at $50{ }^{\circ} \mathrm{C}$, and 45 seconds at $72{ }^{\circ} \mathrm{C}$ for 20 cycles. The samples were incubated before the cyclic reaction at $94{ }^{\circ} \mathrm{C}$ for 3 minutes and after the cyclic reaction at $72{ }^{\circ} \mathrm{C}$ for 10 minutes. An aliquot of the product $(1 \mu \mathrm{L})$ from the first PCR reaction was used in a second reaction amplifying a 479-bp segment of Haemoproteus and Plasmodium lineages using primers HaemF and HaemR2 [53]. The conditions for the second round of PCR assays are as follows: 30 seconds at $50{ }^{\circ} \mathrm{C}$, and 45 seconds at $72{ }^{\circ} \mathrm{C}$ for 35 cycles. PCR screening was carried out three times for each sample, and each plate (96 samples) included two positive controls (one for Haemoproteus and one for Plasmodium) and one negative control. All PCR reactions were performed at a final volume of $25 \mu \mathrm{l}$ using illustra PuReTaq Ready-To-Go ${ }^{\mathrm{TM}}$ beads (GE Healthcare) with freeze-dried, pre-formulated reagents. We ran $5 \mu \mathrm{l}$ of the final product on a $2 \%$ agarose gel to screen for parasite presence. For host individuals infected with haemosporidian parasites, the final PCR product was cleaned with ExoSAP-IT (Thermo Fisher Scientific) prior to sequencing.

The sequencing reaction of $10 \mu \mathrm{l}$ contained $0.25 \mu \mathrm{l}$ BigDye $^{\mathrm{TM}}$ (Thermo Fisher Scientific), $2.275 \mu \mathrm{l}$ BigDye $^{\mathrm{TM}}$, $1 \mu \mathrm{l}$ of each nested secondary PCR primer (HaemF and HaemR2), $1 \mu \mathrm{l}$ of PCR product, and $5.475 \mu \mathrm{l}$ moleculargrade ddH2O. Cycle sequencing was conducted at $94{ }^{\circ} \mathrm{C}$ for $2 \mathrm{~min}$; 40 cycles of amplification at $85^{\circ} \mathrm{C}$ for $10 \mathrm{~s} ; 53$ ${ }^{\circ} \mathrm{C}$ for $10 \mathrm{~s}$ and $60{ }^{\circ} \mathrm{C}$ for $2.5 \mathrm{~min}$. The sequencing reactions were cleaned up using $600 \mu \mathrm{l}$ of Sephadex ${ }^{\circledR}$ G-50 solution per sample prior to analysis on an automated Applied Biosystems (ABI) 3500 Genetic Analyzer. Forward and reverse reads were assembled and edited using Geneious Prime 2019.0.4 (https://www.geneious. com). Mixed sequences, as indicated by double peaks in a chromatogram, were considered co-infections [44]. We identified all sequences at the genus level using the Basic Local Alignment Search Tool (BLAST) feature in the MalAvi database [13] (http://mbio-serv2.mbioekol. lu.se/Malavi/), a database for avian blood parasites. Mitochondrial haplotypes, that is, sequences differing by one or more bases ( $<100 \%$ identity) from known parasite lineages, were considered unique lineages [53].

\section{Statistical analyses}

We carried out each PCR assay three times for each DNA sample in order to obtain a parasite detection history composed of $1 \mathrm{~s}$ and $0 \mathrm{~s}$ for each individual, with 1 signifying at least one detected parasite and 0 indicating no parasite detected. With this detection history, we estimated the probability of parasite detection along with the proportion of individuals infected with blood parasites, 
Table 1 Predicted associations, and explanations, of each predictor variable with haemosporidian parasite prevalence and detection probability

\begin{tabular}{|c|c|c|c|}
\hline Parameter(s) & Predictor variable & $\begin{array}{l}\text { Predicted } \\
\text { direction }\end{array}$ & Explanation \\
\hline \multirow[t]{5}{*}{ Occupancy probability $(\psi)$} & Age & Q & $\begin{array}{l}\text { For adult birds, prevalence of blood parasites decreases with age due to } \\
\text { increased immunocompetence, until old age, in which immunosenes- } \\
\text { cence occurs and is linked to a higher probability of infection [85] }\end{array}$ \\
\hline & Sex (female) & + & $\begin{array}{l}\text { The cost of reproduction is higher in females, decreasing immunocompe- } \\
\text { tence and making females more susceptible to haemosporidian infection } \\
\text { [86]. }\end{array}$ \\
\hline & $\mathrm{BCl}$ [mass (g): tarsus length (mm)] & - & $\begin{array}{l}\text { Individuals in good condition have stronger immunocompetence and are } \\
\text { better able to fight infections }[89,88]\end{array}$ \\
\hline & Migration status & + & $\begin{array}{l}\text { The energetic cost of migration increases with distance, and likely affects } \\
\text { immunocompetence [90]. }\end{array}$ \\
\hline & Nest type (open nest) & + & $\begin{array}{l}\text { Open nests are more exposed to mosquito vectors compared to closed } \\
\text { nests [91] }\end{array}$ \\
\hline Detection probability $(p)$ & PCR run & + & $\begin{array}{l}\text { Differences in results of PCR runs may occur due to variation in parasitemia } \\
\text { between samples, with higher parasitemia associated with higher prob- } \\
\text { ability of detection [92] }\end{array}$ \\
\hline
\end{tabular}

Positive (+), negative (-), or quadratic (Q) predicted associations, and explanation, of each predictor variable for haemosporidian parasite occupancy probability $(\psi$; prevalence) and detection probability ( $p$ ). $\mathrm{BCl}$ is body condition index defined as body mass:tarsus length. PCR is polymerase chain reaction

corrected for detection probability. We analyzed detection histories for avian haemosporidian parasites using the single-season occupancy model in Program MARK [54] to estimate the prevalence (i.e., occupancy) of each genus of parasite for each bird species as well as across species $[49,55]$. In a typical occupancy framework, randomly selected "sites" are surveyed on multiple occasions within a period where occupancy state is assumed not to change. Repeated survey occasions at each site allow the estimation of two parameters: occupancy $(\psi)$, the probability that a site is occupied by the species of interest, and detection probability (p), the probability that the species is detected during a given occasion if the site is occupied [56]. In our study, each blood sample from an individual bird is analogous to a site, the species of interest are Haemoproteus and Plasmodium parasites, and the repeated survey occasions are multiple replicates of PCR assays for each DNA sample. Reinterpreting the model parameters for parasite detection gives $\psi_{\mathrm{i}}$ as the prevalence of a parasite infection, and $p_{\mathrm{i}}$ as the probability of detecting a parasite(s) in site $i$, given the presence of the parasite(s) in the host.

We carried out analyses for Haemoproteus and Plasmodium parasite prevalence separately. We constructed a candidate model set for an all-species analysis that included all birds captured and sampled, as well as a species-specific candidate model set for each host species with at least 20 DNA samples (10 species). In order to address any individual heterogeneity that may exist, we used the random effects model in Program MARK to incorporate any heterogeneity beyond our predictions in each model. Our model set consisted of all possible combinations of predictor variables (Table 1), and we used an information-theoretic approach for model ranking and selection [57]. We calculated Akaike weights $\left(\mathrm{w}_{\mathrm{i}}\right.$; the weight of evidence in favor of each model being the best model compared to the rest of the models in the set) and considered the variables with a cumulative weight greater than 0.5 to be the most important [58].

\section{Results}

In 2017, we captured 232 birds, and in 2018 we captured 206 birds. Of the 438 birds captured, 180 were males, 206 were females, and for the remainder sex could not be determined. We captured 24 hatch-year birds, $135 \mathrm{sec}-$ ond-year birds, and 241 after second-year birds, and we could not determine age in the remaining 38 birds. Body condition indices (mass:tarsus) ranged from 0.20 to 25.71 $\mathrm{g} / \mathrm{mm}$. We collected molecular data from a total of 437 birds belonging to 24 species over the 2 years of the study (Table 2).

\section{Haemosporidian parasite diversity}

In total, we detected 10 Plasmodium and 29 Haemoproteus cytochrome b haplotypes. Thirty-three haplotypes had a $100 \%$ match to current sequences deposited in the MalAvi database (Table 2) [13], and the other six sequences were considered novel haplotypes (GenBank accession numbers MW147676, MW147677, MW147678, MW147679, MW147680, MW147681). The most common Haemoproteus lineages were TURDUS2 and SISKIN1, which were detected in 15 and 13 
individuals, respectively. The most common Plasmodium lineage was PADOM11, which was detected in six individuals. Only one Warbling Vireo (Vireo gilvus) and two Lincoln's Sparrows (Melospiza lincolnii) were found to be infected with both Plasmodium and Haemoproteus. The greatest parasite diversity was obtained from the Wilson's Warbler (Cardellina pusilla; 13), the Warbling Vireo (12), and the White-crowned Sparrow (Zonotrichia leucophrys; 11), which also had some of the largest sample sizes.

\section{Haemoproteus}

We detected Haemoproteus parasites in 109 out of 437 birds, a naïve (without taking detection probability or covariates into account) Haemoproteus prevalence of nearly $25 \%$ (109/437). Nest type and year were considered important variables associated with Haemoproteus prevalence in the all-species analysis, with variable weights of 0.54 and 0.85 (Table 3). Open-cup nesters in 2018 had the highest Haemoproteus overall prevalence, estimated at 38\%, 95\% CI 26.24\%-49.76\% (Fig. 1). Prevalence was similar for cavity and ground nesters in both years and was higher in 2018. In the all-species analysis, we found no evidence of unmodeled heterogeneity using a random effects model (Additional file 1: Table S1). PCR replicate was an important variable when considering detection probability, with a variable weight of 0.99 . Detection probability was estimated at $0.62( \pm 0.07 \mathrm{SE})$ for the first PCR run, 0.38 ( $\pm 0.07 \mathrm{SE}$ ) for the second PCR run, and 0.50 ( $\pm 0.07 \mathrm{SE}$ ) for the third PCR run (Fig. 2).

Among all species, the Warbling Vireo, American Robin (Turdus migratorius), and Wilson's Warbler had the highest naïve Haemoproteus prevalence, at 59\%, $35 \%$, and $32 \%$, respectively. In the species-specific analyses (Additional file 2: Table S2; Additional file 3: Table S3; Additional file 4: Table S4; Additional file 5: Table S5; Additional file 6: Table S6; Additional file 7: Table S7; Additional file 8: Table S8; Additional file 9: Table S9; Additional file 10: Table S10; Additional file 11: Table S11), all species had an estimated individual heterogeneity of nearly zero. In terms of prevalence $(\psi)$, sex was considered an important variable for the Ruby-crowned Kinglet (Regulus calendula), the White-crowned Sparrow, and Wilson's Warbler (Fig. 3), with variable weights of $0.57,0.54$, and 0.51 , respectively (Table 4 ). Body condition index (BCI) was also considered an important covariate of prevalence for the Red-breasted Nuthatch (Sitta canadensis) and the Ruby-crowned Kinglet (Fig. 4), with variable weights of 0.69 and 0.84 , respectively (Table 4). No species had variable weights above 0.5 for age or year. For detection probability $(p)$, PCR run was an important variable for the Lincoln's Sparrow and the
White-crowned Sparrow, with variable weights of 0.96 and 0.50 , respectively (Fig. 5).

\section{Plasmodium}

We detected Plasmodium parasites in at least one PCR replicate in 23 out of 437 birds, which is a total naïve Plasmodium prevalence of $5.3 \%$. When analyzing all species together, we detected no heterogeneity using a random effects model. We found no predictor variable with a cumulative variable AICc weight of at least 0.5 , and therefore none of our hypothesized variables were considered important in predicting Plasmodium infection in the all-species analysis.

Wilson's Warbler and Lincoln's Sparrow had the greatest number of infected individuals per species, with three birds positive for Plasmodium in each. Because of the low number of positives per species, species-specific analyses could not be carried out for Plasmodium prevalence.

\section{Discussion}

In this study, we present baseline knowledge of haemosporidian parasite presence, prevalence, and diversity across a suite of avian species in the Colorado Rocky Mountains. Among the 438 birds of 24 species sampled, 39 unique haemosporidian parasite haplotypes were detected, 21 host species had at least one infected individual, and Haemoproteus parasites had a larger host breadth and occurred at much higher prevalence than Plasmodium. In addition, six novel haplotypes were detected among three different species. Using an occupancy-modeling framework to account for imperfect detection of avian blood parasites, we found that nest type is an important species-level factor influencing Haemoproteus parasitism at our study site, with open-cup nesters having a higher prevalence than cavity and ground nesters. We also found that sex and BCI are important individual-level factors associated with Haemoproteus parasitism in some species, with males and birds with higher BCI having a higher blood parasite prevalence. In addition, we found that out of the 24 hatch-year birds that were sampled during the study, seven were positive for Haemoproteus blood parasites, meaning that local transmission was taking place at our sample site.

\section{Haemosporidian lineage diversity}

Diversity of haemosporidian parasites in wild birds was high, with a total of 39 lineages of Haemoproteus and Plasmodium from 21 of the 24 avian species that were sampled (Table 2). Plasmodium parasites are considered 
Table 2 Host bird species sampled and haemosporidian lineages detected in each host species

\begin{tabular}{|c|c|c|c|c|}
\hline Bird species (nest type) & $\begin{array}{l}\text { \# Sampled } \\
\text { individuals }\end{array}$ & $\begin{array}{l}\text { \# Plasmodium } \\
\text { infections } \\
\text { detected }\end{array}$ & $\begin{array}{l}\text { \# Haemoproteus } \\
\text { infections } \\
\text { detected }\end{array}$ & Molecular lineages (\# detected in each species) \\
\hline American Robin (Turdus migratorius; $T$ ) & 28 & 2 & 11 & $\begin{array}{l}\text { H_JUHYE03 (1), H_TURDUS2 (3), H_PHYBOR04 } \\
\text { (1), H_VIGIL07 (1), H_TUMIG07 (1), H_TUMIG08 } \\
\text { (2), H_POEATR01 (1), H_DENADE01 (1), P- } \\
\text { LAIRI01 (2) }\end{array}$ \\
\hline $\begin{array}{l}\text { American Three-toed Woodpecker (Picoides } \\
\text { dorsalis; C) }\end{array}$ & 1 & 0 & 0 & \\
\hline Brown Creeper (Certhia americana; $\mathrm{C}$ ) & 7 & 0 & 1 & H_SISKIN1 (1) \\
\hline Chipping Sparrow (Spizella passerine; G) & 2 & 0 & 1 & H_VIGIL07 (1) \\
\hline $\begin{array}{l}\text { Cordilleran Flycatcher (Empidonax occidentalis; } \\
\text { T) }\end{array}$ & 20 & 1 & 1 & H_PHYBOR04 (1), P_PADOM11 (1) \\
\hline Dark-eyed Junco (Junco hyemalis; G) & 31 & 1 & 6 & $\begin{array}{l}\text { H_VIOLIO5 (2), H_SISKIN1 (3), H_TURDUS2 (1), } \\
\text { P_WW3 (1) }\end{array}$ \\
\hline Golden-crowned Kinglet (Regulus satrapa; $\mathrm{T}$ ) & 2 & 1 & 1 & H_MELCAR01 (1),P_LAIRI01 (1) \\
\hline Green-tailed Towhee (Pipilo chlorurus; G) & 1 & 0 & 0 & \\
\hline Hairy Woodpecker (Dryobates villosus; C) & 3 & 0 & 0 & \\
\hline Hermit Thrush (Catharus guttatus; G) & 5 & 0 & 2 & H_JUHYEO3 (1), H_TUMIG07 (1) \\
\hline House Wren (Troglodytes aedon; C) & 6 & 0 & 1 & H_GYMSAL01 (1) \\
\hline Lincoln's Sparrow (Melospiza lincolnii; G) & 63 & 4 & 13 & $\begin{array}{l}\text { H_GYMSAL01 (1), H_TURDUS2 (3), H_VIGIL07 (3), } \\
\text { H_MELCAR01 (1), H_TUMIG08 (1), H_PHY- } \\
\text { BOR04 (1), H_DENADE01 (2), H_TUMIG06 (1), } \\
\text { P_CATUST06 (1), P_PADOM11 (1), P_WW3 (1), } \\
\text { P_BAEBICO2 (1) }\end{array}$ \\
\hline MacGillivray's Warbler (Geothlypis tolmiei; G) & 6 & 0 & 1 & H_PHYBOR01 (1) \\
\hline Mountain Chickadee (Poecile gambeli; C) & 22 & 2 & 3 & $\begin{array}{l}\text { H_SISKIN1 (1), H_TURDUS2 (1), H_PHYBOR01 } \\
(1), \text { P_WW3 (2) }\end{array}$ \\
\hline Northern Flicker (Colaptes auratus; C) & 5 & 0 & 2 & $\begin{array}{l}\text { H_GYMSAL01 (1), H_ZOCAP08 (1), H_SISKIN1 (1), } \\
\text { H_MELCAR01 (1) }\end{array}$ \\
\hline Pine Siskin (Spinus pinus; $T$ ) & 45 & 1 & 8 & $\begin{array}{l}\text { H_TABI10 (1), H_JUHYEO3 (1), H_SISKIN1 (2), } \\
\text { H_PASILIO1 (1), H_TURDUS2 (2), H_MELICAR01 } \\
\text { (1),P_PADOM11 (1) }\end{array}$ \\
\hline Red-breasted Nuthatch (Sitta canadensis; C) & 24 & 0 & 3 & H_SISKIN1 (2), H_VIGIL07 (1) \\
\hline Red-naped Sapsucker (Sphyrapicus nuchalis; C) & 6 & 0 & 1 & H_TUMIG07 (1) \\
\hline Ruby-crowned Kinglet (Regulus calendula; $\mathrm{T}$ ) & 23 & 0 & 5 & $\begin{array}{l}\text { H_SISKIN1 (1), H_ZOCAP08 (1), H_TURDUS2 (1), } \\
\text { H_TUMIG06 (1), H_TUMIG07 (1), H_VIGILO7 (1) }\end{array}$ \\
\hline Tree Swallow (Tachycineta bicolor; C) & 12 & 0 & 2 & H_GYMSAL01 (1), H_TUMIG07 (1) \\
\hline Warbling Vireo (Vireo gilvus; $T$ ) & 22 & 3 & 14 & $\begin{array}{l}\text { H_TUMIG07 (2), H_TUPHI01 (2), H_PHYBOR04 } \\
\text { (2), H_TUMIG08 (1), H_SETAUD08 (1), H_TABIO2 } \\
\text { (1), H_VIGIL07 (2), H_VIGIL01 (1), H_PERCAN07 } \\
\text { (2),H_MELCAR01 (1), P_PADOM11 (2), P_BAE- } \\
\text { BICO2 (1) }\end{array}$ \\
\hline $\begin{array}{l}\text { White-crowned Sparrow } \\
\text { (Zonotrichia leucophrys; G) }\end{array}$ & 47 & 2 & 13 & $\begin{array}{l}\text { H_SISKIN1 (2), H_TUMIG07 (2), CATUST16 (1), } \\
\text { H_PHYBOR04 (1), H_TUMIG06 (1), H_TABIO2 } \\
\text { (1), H_MELCARO1 (2), H_TURDUS2 (1), H_- } \\
\text { VIGIL01 (1), H_DENEDE01 (1), P_MELMEL02 (1), } \\
\text { P_GEOTRI09 (1) }\end{array}$ \\
\hline Wilson's Warbler (Cardellina pusilla; G) & 51 & 5 & 15 & $\begin{array}{l}\text { H_TURDUS2 (2), H_PHYBOR04 (2), H_SIS- } \\
\text { KIN1 (1), H_MELCARO1 (2), H_TUMIG07 (1), } \\
\text { H_VIGIL07 (2), H_GRBRU02 (1), H_VIGIL01 (1), } \\
\text { H_DENADEO1 (2), H_LAIRI01 (1), P_CATUST06 } \\
\text { (2), P_GEOTRI09 (1), P_GASAN01 (2) }\end{array}$ \\
\hline Yellow-rumped warbler (Setophaga coronate; T) & 11 & 2 & 4 & H_TABI10 (2), H_VIGIL07 (2), P_BAEBICO2 (2) \\
\hline
\end{tabular}


Table 3 Cumulative Akaike information criterion (AICc) variable weights for variables considered in the all-species analysis for Haemoproteus prevalence

\begin{tabular}{ll}
\hline Variable & Variable weight \\
\hline$\psi($ sex $)$ & 0.21 \\
$\psi($ age $)$ & 0.05 \\
$\psi$ (migration) & 0.19 \\
$\psi($ nest $)$ & 0.54 \\
$\psi($ year $)$ & 0.85 \\
$\psi(B C l)$ & 0.27 \\
$p(P C R$ run $)$ & 0.99
\end{tabular}

Variables with a cumulative weight greater than 0.5 (italics) are considered important. $\psi$ variables are those considered when evaluating prevalence. The $p$ variables are those considered when evaluating detection probability. "PCR run"indicates the three PCR replicates carried out for each sample. "Nest" indicates nest type (open, ground, or cavity). $\mathrm{BCl}$ is body condition index defined as the ratio of body mass $(\mathrm{g})$ to tarsus length $(\mathrm{mm})$ for each individual

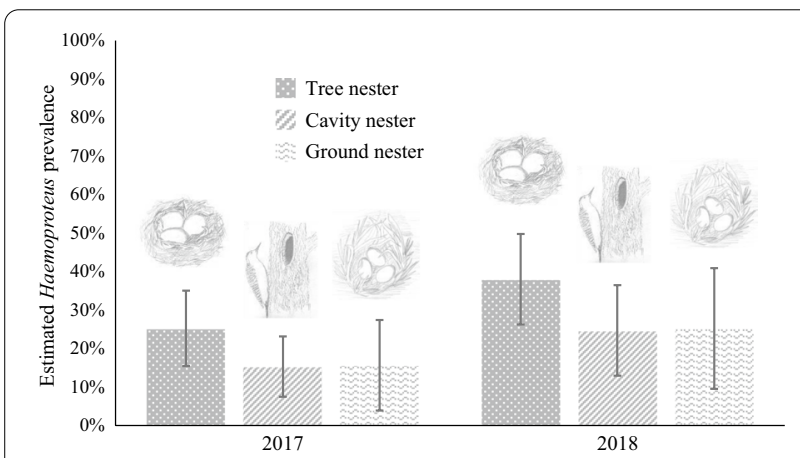

Fig. 1 Estimated avian Haemoproteus prevalence (95\% Cl) for nest types and years in the Rocky Mountains

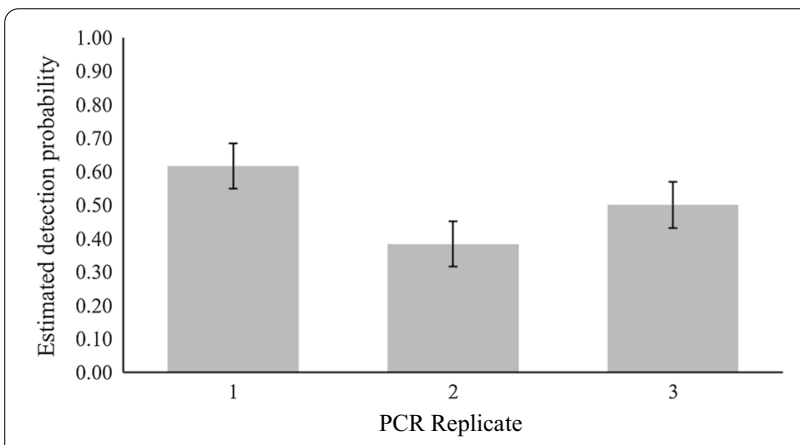

Fig. 2 Haemoproteus detection probability $(p \pm$ SE) for PCR replicates in all-species analysis of birds in the Rocky Mountains

generalists in terms of host breadth, while Haemoproteus are generally considered more host-specific [53]. However, we identified Haemoproteus in a wider range of bird

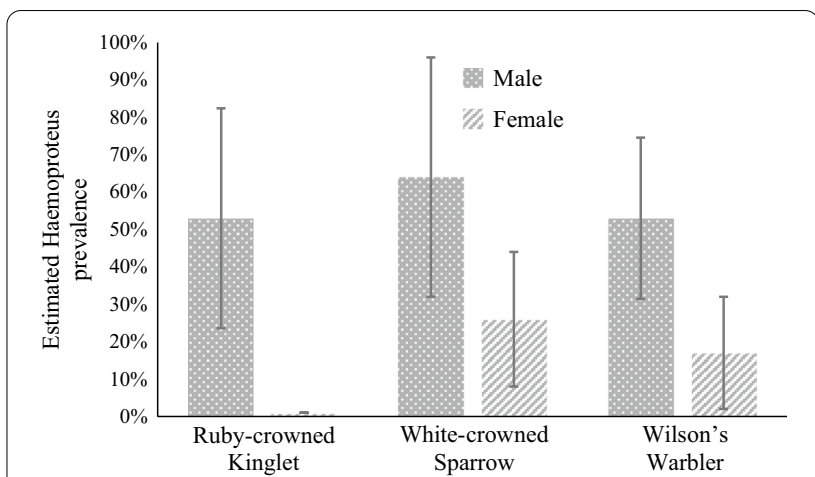

Fig. 3 Haemoproteus prevalence (95\% Cl) for male and female Ruby-crowned Kinglet, White-crowned Sparrow, and Wilson's Warbler

Table 4 Cumulative variable Akaike information criterion (AICc) weights for variables considered in each species-specific analysis for Haemoproteus prevalence

\begin{tabular}{llllll}
\hline Species & \multicolumn{5}{l}{ Cumulative Variable Weights } \\
\cline { 2 - 6 } & $\psi($ sex $)$ & $\psi$ (age) & $\psi($ year $)$ & $\psi(\mathrm{BCl})$ & $\mathrm{p}$ (PCR replicate) \\
\hline American Robin & 0.33 & 0.09 & 0.26 & 0.32 & 0.14 \\
Lincoln Sparrow & 0.29 & 0.25 & 0.27 & 0.26 & 0.96 \\
Mountain Chickadee & - & - & 0.22 & 0.23 & 0.06 \\
Pine Siskin & 0.27 & 0.25 & 0.34 & 0.39 & 0.24 \\
Red-breasted Nut- & 0.07 & - & - & 0.69 & - \\
$\quad$ hatch & & & & & \\
Ruby-crowned & 0.57 & - & - & 0.84 & - \\
$\quad$ Kinglet & & & & & \\
Dark-eyed Junco & 0.35 & 0.05 & 0.03 & 0.21 & 0.30 \\
Warbling Vireo & 0.33 & 0.04 & - & 0.38 & 0.30 \\
White-crowned & 0.54 & 0.10 & 0.40 & 0.35 & 0.50 \\
$\quad$ Sparrow & & & & & \\
Wilson's Warbler & 0.51 & 0.07 & 0.42 & 0.25 & 0.08 \\
\hline
\end{tabular}

Variables with a cumulative variable AICc weight greater than 0.5 (italics) are considered important. Cells with a dash indicate that models would not converge with the inclusion of that variable. $\psi$ variables are those considered when evaluating prevalence. $p$ variables are those considered when evaluating detection probability. "PCR run" indicates the three PCR replicates carried out for each sample. "Nest" indicates nest type (open, ground, or cavity). BCl is body condition index defined as the ratio of body mass $(\mathrm{g})$ to tarsus length $(\mathrm{mm})$ for each individual

species than Plasmodium and found that Haemoproteus parasites were more prevalent overall.

Despite the small sample sizes for some host species, some patterns were still apparent largely in the family Turdidae. One lineage, TURDUS2, infects many families of birds throughout Europe [60], Asia [61], and the United States [62], yet most detections have occurred in the Turdidae, including robins and other thrushes. Accordingly, American Robins at our study site had the highest proportion of TURDUS2 detections among 


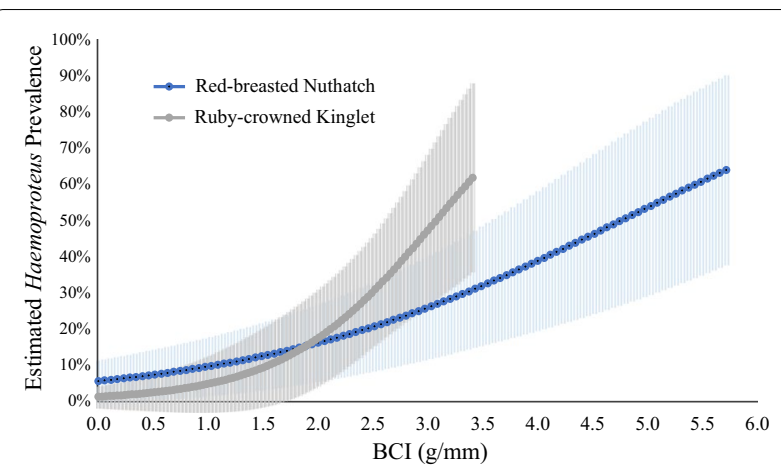

Fig. 4 Haemoproteus prevalence $(95 \% \mathrm{Cl})$ and body condition index for Red-breasted Nuthatch and Ruby-crowned Kinglet

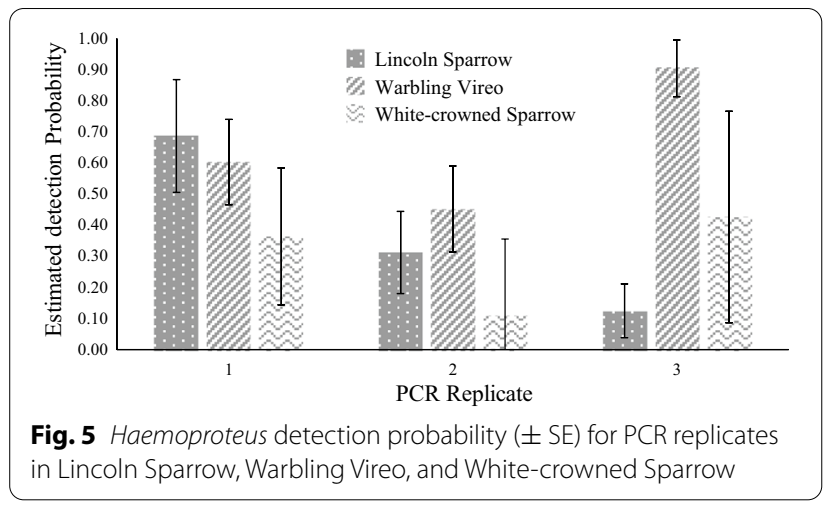

species and may act as a reservoir for this parasite lineage. The lineage TUMIG07 has only been detected in the American Robin and Hermit Thrush (Catharus guttatus) in Alaska [62]. In our study, TUMIG07 was present in these species and six other hosts at our site. The VIGIL07 lineage has only been detected in the Vireonidae family in California [63], New Mexico (Marroquin-Flores unpublished data), and Michigan [42], and in our study the Warbling Vireo had the highest proportion of positive individuals. Of the seven detections of the TUMIG08 lineage in the MalAvi database, four have been from the American Robin [62]. Accordingly, two of the four detections of this lineage at our study site were from American Robins, with one detection in a Lincoln Sparrow and the other in a Warbling Vireo. The POETR01 lineage has been mainly detected in the Thrush family as well [61], and our one detection of this lineage was in an American Robin, in agreement with previous detections.

\section{Patterns across host species}

When analyzing Haemoproteus prevalence across host species, nest type and year were important variables associated with infection (Fig. 1). Although some studies have found contradicting results [37, 38 and 64], opencup nesting has been linked to higher Haemoproteus prevalence in many studies, such as Gonzales et al. [40], Smith et al. [42], and Fechio [43]. Higher prevalence in open-cup nesters may indicate that Haemoproteus vectors-biting midges-are more likely to come in contact with species that have open-cup nests than with ground or cavity nesters, perhaps because open-cup nesters are more vulnerable to exposure to blood feeding by the vectors.

Overall Haemoproteus prevalence also displayed marked variation between years in our study, with 2018 higher than 2017 (Fig. 3). Interannual variation in avian blood parasite prevalence is common and has been found in many studies, including Bensch et al. [64], Wood et al. [23], Lachish et al. [24], and Podmokła et al. [65]. One potential explanation is that the vectors responsible for Haemoproteus transmission fluctuate in abundance in response to weather variation (e.g., temperature and rainfall), which alters the habitat and microclimate they require for breeding to conditions that are more favorable for vectors. Alternatively, annual variation in host demography and population dynamics could also play a role in driving this annual variation in prevalence [66, 67].

Age, sex, BCI, and migration were not considered important variables across species in our study, although they have been linked to higher haemosporidian parasite prevalence in other studies, e.g., Hatchwell et al. [68], Deviche et al. [69], Garvin et al. [70], and Calero-Riestra and Garcia [71]. Further studies are needed to address the influence of host traits on patterns of avian haemosporidian parasite infection and to determine whether such patterns exist and persist at larger spatial scales and across a wider host-parasite community.

When analyzing Plasmodium prevalence among host species, no associations were found between prevalence and species-level traits, likely due to the low number of individuals that were positive for the parasite. Elevation governs the distribution of parasites belonging to different genera, with Plasmodium parasites being more prevalent at lower altitudes and Haemoproteus parasite prevalence increasing with elevation [25]; our site is very high, which may explain the lack of Plasmodium detections. Accordingly, Eisen et al. [36] found that Culex spp. mosquitoes, the main vectors of Plasmodium parasites, were not yet established in areas in and around Rocky Mountain National Park at similar elevations as our study site. Associations between exposure to mosquitoes and Plasmodium prevalence across host species has been 
demonstrated [28], supporting the idea that Plasmodium vectors may be absent or present in low numbers at our study site.

\section{Patterns of Haemoproteus infection within individual species}

Sex was associated with Haemoproteus infection in the Ruby-crowned Kinglet, White-crowned Sparrow, and Wilson's Warbler (Fig. 4). Sex-related differences in haemosporidian parasite prevalence are often observed in nature; however, sex bias in parasitism often varies between and within host-parasite systems [72]. Contrary to our prediction, our study demonstrated a strong malebiased parasite prevalence in the three species mentioned above, with the Ruby-crowned Kinglet having the largest difference between sexes (53\% in males vs. $1 \%$ in females). Although the greater stress of reproduction in females might translate to weakened immune responses and higher prevalence [73], there is overwhelming evidence that sex-associated hormones can directly influence the differential susceptibility of each sex to infections [74]. For example, testosterone has immunosuppressive effects in many species, leading to higher susceptibility of males to parasite infections [75]. This is not the case for every host-parasite relationship, as was illustrated by the lack of an association between parasite prevalence and sex in the other seven species that we analyzed.

Body condition index (BCI) was positively associated with Haemoproteus infection in the Red-breasted Nuthatch and the Ruby-crowned Kinglet when analyzed separately (Fig. 5). Similar results have been found in the American Kestrel (Falco sparverius), the Yellow-rumped Warbler (Setophaga coronate), and the Great Tit (Parus major) $[78,79]$. Although the reason for this positive correlation is unknown, it may be due to the lower capture probability in infected individuals. If infected individuals with low body condition are less active and are less likely to fly into mist nets, that leaves only infected individuals with greater body condition to be caught. Similarly, if individuals with low body condition are unable to survive the acute stage of Haemoproteus infection, then this may leave more infected individuals with higher body condition. The other eight species in our study did not show an apparent relationship between prevalence and BCI, which is a common result in wildlife studies given that host condition and its responsiveness to infection could change in response to foraging resources that fluctuate in space and time [80,81]. Some parasites cause minimal or no effects on condition in certain host taxa [81], and some infections might exert negative fitness effects only during stressful periods or under resource limitation [82, 83].
We found no relationship between Haemoproteus prevalence and individual-level traits (sex, age, BCI) in the American Robin, Mountain Chickadee (Poecile gambeli), Pine Siskin (Carduelis pinus), or Dark-eyed Junco (Junco hyemalis), contrary to our hypotheses. Our results suggest that the individual-level traits examined in this study may not be important predictors of Haemoproteus infection for all species.

\section{Detection probability}

PCR replicate was an important variable associated with detection probability for Haemoproteus infection for three species (Lincoln Sparrow, Warbling Vireo, and White-Crowned Sparrow) as well as for the all-species analysis, with PCR results varying among the three PCR runs (Figs. 2 and 5). Nested PCR assays for haemosporidian parasites are known to be vulnerable to falsenegative results for samples with low parasite intensities [84], which is most likely responsible for the variation we found between PCR replicates.

Detection probability for Plasmodium parasites was lower than for Haemoproteus, consistent with the idea of lower detection in blood samples [84], because Plasmodium enters latent, exoerythrocytic phases during chronic infection and may even be absent in the blood stream [10]. Thus, sampling peripheral blood may not allow for detection of all true infections with Plasmodium, leading to underestimates of prevalence.

\section{Conclusion}

Our results suggest that open-cup nesting birds in the Colorado Rocky Mountains are commonly infected with avian blood parasites, and that male Rubycrowned Kinglets, White-crowned Sparrows, and Wilson's Warblers have higher prevalence than females of these species. We present baseline knowledge of blood parasite presence, prevalence, and diversity across avian species in the Colorado Rocky Mountains, providing a strong foundation for subsequent studies. With climate change expected to support the expansion of avian blood parasite distributions, such that monitoring avian haemosporidian parasites should continue in order to detect potential climate-related changes in prevalence and diversity over time. Our study is the only avian blood parasite survey conducted in the Colorado Rocky Mountains, to date; additional research in this area examining host-parasite relationships would help to determine whether anthropogenic changessuch as climate change-leading to potential changes in vector communities or parasite distributions may pose a threat to resident avian populations. 


\section{Supplementary Information}

The online version contains supplementary material available at https://doi. org/10.1186/s13071-021-04612-w.

Additional file 1: Table S1. Model rankings exploring factors affecting detection probability $(p)$ and prevalence $(\psi)$ of Haemoproteus parasites across host species.

Additional file 2: Table S2. Model rankings exploring factors affecting detection probability $(p)$ and prevalence $(\psi)$ of Haemoproteus parasites in American Robins.

Additional file 3: Table S3. Model rankings exploring factors affecting detection probability $(p)$ and prevalence $(\psi)$ of Haemoproteus parasites in Lincoln's Sparrows.

Additional file 4: Table S4. Model rankings exploring factors affecting detection probability $(p)$ and prevalence $(\psi)$ of Haemoproteus parasites in Mountain Chickadees.

Additional file 5: Table S5. Model rankings exploring factors affecting detection probability $(p)$ and prevalence $(\psi)$ of Haemoproteus parasites in Pine Siskins.

Additional file 6: Table S6. Model rankings exploring factors affecting detection probability $(p)$ and prevalence $(\psi)$ of Haemoproteus parasites in Red-breasted Nuthatches.

Additional file 7: Table S7. Model rankings exploring factors affecting detection probability $(p)$ and prevalence $(\psi)$ of Haemoproteus parasites in Ruby-crowned Kinglets.

Additional file 8: Table S8. Model rankings exploring factors affecting detection probability $(p)$ and prevalence $(\psi)$ of Haemoproteus parasites in Dark-eyed Juncos.

Additional file 9: Table S9. Model rankings exploring factors affecting detection probability $(p)$ and prevalence $(\psi)$ of Haemoproteus parasites in Warbling Vireos.

Additional file 10: Table S10. Model rankings exploring factors affecting detection probability $(p)$ and prevalence $(\psi)$ of Haemoproteus parasites in White-crowned Sparrows.

Additional file 11: Table S11. Model rankings exploring factors affecting detection probability $(p)$ and prevalence $(\psi)$ of Haemoproteus parasites in Wilson's Warblers.

\section{Acknowledgements}

We would like to thank the Colorado Chapter of the Wildlife Society for funding through their Small Grants Program. Our sincere thanks to Seth Webb and all of the staff Colorado State University Mountain Campus for approval and support in collecting avian blood samples on the premises. We thank field assistants Arlene Cortez and Martin Rodriguez, as well as laboratory assistants Jarred Bland and Valeria Aspinall. Thanks to Doreen Griffin for sequence training and guidance. Permission for capturing birds and taking blood samples from birds in Colorado was approved by the Colorado State University Institution for Animal Care and Use Committee (Protocol 17-7309A).

\section{Authors' contributions}

$M R$ and $\mathrm{KH}$ conceived the idea. MR, KH, and PD designed the field study. MR carried out the laboratory work with the instruction and laboratory equipment from $\mathrm{KH}$ and AP. MR conducted the analysis with guidance from PD. MR wrote the paper, and KH, PD, and AP reviewed the manuscript. All authors read and approved the final manuscript

\section{Funding}

This study was funded in part by the Colorado Chapter of The Wildlife Society's Small Grants Program and the National Science Foundation's Graduate Research Fellowship Program.

\section{Availability of data and materials}

The data sets used and/or analyzed during the current study are available from the corresponding author on reasonable request.

\section{Ethics approval and consent to participate}

Permission for capturing and taking blood samples from birds was approved by the Colorado State University Institution for Animal Care and Use Committee (Protocol 17-7309A).

\section{Consent for publication}

Not applicable.

\section{Competing interests}

The authors declare that they have no competing interests.

\section{Author details}

${ }^{1}$ Department of Fish, Wildlife and Conservation Biology, Colorado State University, Fort Collins, Colorado, USA. ${ }^{2}$ National Wild life Research Center, U.S. Department of Agriculture, Fort Collins, Colorado, USA.

Received: 26 August 2020 Accepted: 27 January 2021

Published online: 08 March 2021

\section{References}

1. Tompkins DM, Begon M. Parasites can regulate wildlife populations. Parasitol Today. 1999;15:311-3.

2. Schmid HP. Evolutionary parasitology: the integrated study of infections, immunology, ecology, and genetics. New York: Oxford University Press; 2011.

3. Hochachka WM, Dhondt AA. Density-dependent decline of host abundance resulting from a new infectious disease. Proc Natl Acad Sci. 2000;97:5303-6.

4. Ricklefs RE, Medeiros M, Ellis VA, Svensson-Coelho M, Blake JG, Loiselle $B A$, et al. Avian migration and the distribution of malaria parasites in New World passerine birds. J Biogeogr. 2016;44:1113-23.

5. Laine AL. Role of coevolution in generating biological diversity: spatially divergent selection trajectories. J Exp Bot. 2009:60:2957-70.

6. Yuill TM. Diseases as components of mammalian ecosystems: mayhem and subtlety. Can J Zool. 1986;65:1061-6.

7. Minchella DJ, Scott ME. Parasitism: A cryptic determinant of animal community structure. Trends Ecol Evol. 1991;6:250-4.

8. Gulland F. The impact of infectious diseases on wild animal populations: a review In: Grenfell BT, Dobson AP, Moffatt HK, editors. Ecology of Infectious Diseases in Natural Populations. Cambridge University Press; 1995;20-51

9. Holmes JC. Polulation regulation: a dynamic complex of interactions. Wildl Res. 1995;22:11-9.

10. Valkiunas G. Avian malaria parasites and other haemosporidia. Boca Raton, FL: CRC Press; 2004.

11. Witsenburg F, Salamin N, Christe P. The evolutionary host switches of Polychromophilus: a multi-gene phylogeny of the bat malaria genus suggests a second invasion of mammals by a haemosporidian parasite. Malaria J. 2012;11:53-62.

12. Staats CM, Schall JJ. Malarial parasites (Plasmodium) of Anolis lizards: biogeography in the Lesser Antilles. Biotropica. 1996;1:388-93.

13. Bensch S, Hellgren O, Perez-Tris JA. MalAvi: a public database of malaria parasites and related haemosporidians in avian hosts based on mitochondrial cytochrome b lineages. Mol Ecol Resour. 2009;9:1353-8.

14. Valkiunas G, Palinauskas V, Ilgunas M, Bukauskaite D, Dimitrov D, Bernotiene $\mathrm{R}$, et al. Molecular characterization of five widespread avian haemosporidian parasites (Haemosporida), with perspectives on the PCR-based detection of haemosporidians in wildlife. Parasitol Res. 2014;113:2251-63.

15. Mullen GR, Durden LA. Medical and veterinary entomology. Burlington, MA: Academic Press; 2009.

16. Bosholn M, Fecchio A, Silveira P, Braga ÉM, Anciães M. Effects of avian malaria on male behaviour and female visitation in lekking blue-crowned manakins. J Avian Biol. 2016;47:457-65.

17. van Riper C, van Riper SG. The epizootiology and ecological significance of malaria in Hawaiian land birds. Ecol Monogr. 1986;56:327-44.

18. Atkinson CT, Dusek RJ, Woods KL, Iko WM. Pathogenicity of avian malaria in experimentally-infected Hawaii amakihi. J Wildl Dis. 2000;36:197-204. 
19. Ortego J, Cordero PJ, Aparicio JM, Calabuig G. Consequences of chronic infections with three different avian malaria lineages on reproductive performance of lesser kestrels (Falco naumanni). J Ornithol. 2008;149:337-43.

20. Knowles SCL, Wood MJ, Sheldon BC. Context-dependent effects of parental effort on malaria infection in a wild bird population, and their role in reproductive trade-offs. Oecologia. 2010;164:87-97.

21. Asghar M, Hasselquist D, Hansson B, Zehtindjiev P, Westerdahl SBH. Hidden costs of infection: chronic malaria accelerates telomere degradation and senescence in wild birds. Science. 2015;347:436-8.

22. LaPointe DA, Goff ML, Atkinson CT. Comparative susceptibility of introduced forest dwelling mosquitoes in Hawai'i to avian malaria Plasmodium relictum. J Parasitol. 2005;91:843-9.

23. Wood MJ, Cosgrove CL, Wilkin TA, Knowles SC, Day KP, Sheldon BC. Within-population variation in prevalence and lineage distribution of avian malaria in blue tits Cyanistes coeruleus. Mol Ecol. 2007;16:3263-73.

24. Lachish S, Knowles SC, Alves R, Wood MJ, Sheldon BC. Infection dynamics of endemic malaria in a wild bird population: parasite species-dependent drivers of spatial and temporal variation in transmission rates. Ecol. 2011:80:1207-16.

25. Rooyen JV, Lalubin F, Glaizot O, Christe P. Altitudinal variation in haemosporidian parasite distribution in great tit populations. Parasit Vectors. 2013;6:139-49.

26. Balenghien T, Fouque F, Sabatier P, Bicout DJ. Horse-, bird-, and humanseeking behavior and seasonal abundance of mosquitoes in a West Nile Virus focus of Southern France. J Med Entomol. 2006;43:936-46.

27. Stearns SC. The evolution of life histories. New York: Oxford University Press; 1992

28. Medeiros MC, Ricklefs RE, Brawn JD, Hamer GL. Plasmodium prevalence across avian host species is positively associated with exposure to mosquito vectors. J Parasitol. 2015;142:1612-20.

29. LaPointe DA. Avian malaria in Hawai'i: The distribution, ecology and vector potential of forest-dwelling mosquitoes. J Parisitol. 2001;91:843-9.

30. Eisen L, Bolling BG, Blair CD, Beaty BJ, Moore CG. MRBAYES: bayesian inference of phylogenetic trees. J Bioinform. 2001;17:754-5.

31. Barker CM, Bolling BG, Black WC, Moore CG, Eisen L. Mosquitoes and West Nile virus along a river corridor from prairie to montane habitats in eastern Colorado. J Vector Ecol. 2009:34:276-93.

32. Samuel MD, Woodworth BL, Atkinson CT, Hart PJ, LaPointe DA. Avian malaria in Hawaiian forest birds: infection and population impacts across species and elevations. Ecosphere. 2015;6:1-21.

33. LaPointe DA, Goff ML, Atkinson CT. Thermal constraints to the sporogonic development and altitudinal distribution of avian malaria Plasmodium relictum in Hawai'i. J Parasitol. 2010;96:318-24.

34. Atkinson CT, Utzurrum RB, LapointeDA, CampRJ, Crampton LH, Foster JT, et al. Changing climate and the altitudinal range of avian malaria in the Hawaiian Islands-an ongoing conservation crisis on the island of Kaua'i. Glob Change Biol. 2014;20:2426-36.

35. Paz S. Climate change impacts on West Nile virus transmission in a global context. Philos Trans R Soc. 2015;370:20130561.

36. Eisen L, Bolling BG, Blair CG, Beaty BJ, Moore CJ. Mosquito species richness, composition, and abundance along habitat-climate-elevation gradients in the northern Colorado front range. J Med Entomol. 2008:45:800-11.

37. Fecchio A, Ellis VA, Bell JA, Andretti CB, D'horta FM, Silva AM, et al. Avian malaria, ecological host traits and mosquito abundance in southeastern Amazonia. Parasitol. 2017; 144:1117-32.

38. Fecchio A, Lima MR, Svensson-Coelho M, Marini MA, Ricklefs RE. Structure and organization of an avian haemosporidian assemblage in a Neotropical savanna in Brazil. Parasitol. 2013;140:181.

39. Popescu M, Trychta MR, Jackson EG, Selman JB, Houston AE, Collins MD. Avian haemosporidian prevalence and its relationship to host traits in Western Tennessee. J Ornithol. 2020;161:995-1010.

40. Gonzalez AD, Matta NE, Ellis VA, Miller ET, Ricklefs RE, Gutierrez HR. Mixed species flock, nest height, and elevation partially explain avian haemoparasite prevalence in Colombia. PLoS ONE. 2014. https://doi.org/10.1371/01006 95.

41. Matthews AE, Ellis VA, Hanson AA, Roberts JR, Ricklefs RE, Collins MD. Avian haemosporidian prevalence and its relationship to host life histories in eastern Tennessee. J Ornithol. 2015;157:533-48.
42. Smith JD, Gill SA, Baker KM, Vonhof MJ. Prevalence and diversity of avian Haemosporida infecting songbirds in southwest Michigan. Parasitol Res. 2018:117:471-89.

43. Fecchio A, Lima MR, Silveira P, Braga ÉM, Marini MÂ. High prevalence of blood parasites in social birds from a neotropical savanna in Brazil. EmuAustral Ornithol. 2011;111:132-8.

44. Lutz HL, Hochachka WM, Engel Jl, Bell JA, Tkach W, Bates JM, et al. Parasite prevalence corresponds to host life history in a diverse assemblage of Afrotropical birds and haemosporidian parasites. PLoS ONE. 2015:10:e0121254.

45. McKay AF, Hoye BJ. Are migratory animals superspreaders of infection? Integr Comp Biol. 2016;56:260-7.

46. Bueno MG, Lopez RP, de Menezes RM, Costa-Nascimento J, Lima GF, Araujo RA, et al. Identification of Plasmodium relictum causing mortality in penguins (Spheniscus magellanicus) from Sao Paulo Zoo. Brazil Vet Parasitol. 2010;173:123-7.

47. Yoshimura A, Koketsu M, Bando H, Saiki E, Suzuki M, Watanabe Y, et al. Phylogenetic comparison of avian haemosporidian parasites from resident and migratory birds in northern Japan. J Wildl Dis. 2014;50:235-42.

48. Mosher BA, Brand AB, Wiewel AN, Miller DA, Gray MJ, Miller DL, et al. Estimating occurrence, prevalence, and detection of amphibian pathogens: insights from occupancy models. J Wildl Dis. 2019;5:563-75.

49. MacKenzie DI, Nichols JD, Royle JA, Pollock KH, Bailey L, Hines JE. Occupancy estimation and modeling: inferring patterns and dynamics of species occurrence. Burlington, MA: Elsevier; 2018.

50. McClintock BT, Nichols JD, Bailey LL, MacKenzie DI, Kendall W, Franklin AB. Seeking a second opinion: uncertainty in disease ecology. Ecol. 2010;13:659-74

51. Lachish S, Gopalaswamy AM, Knowles SC, Sheldon BC. Site-occupancy modelling as a novel framework for assessing test sensitivity and estimating wildlife disease prevalence from imperfect diagnostic tests. Ecol. 2012:3:339-48.

52. Pyle P. Identification guide to North American birds: a compendium of information on identifying, ageing, and sexing "near-passerines" and passerines in the hand. Bolinas, CA: Slate Creek Press; 1997.

53. Hellgren O, Waldenstromm J, Bensch S. A new PCR assay for simultaneous studies of Leucocytozoon, Plasmodium, and Haemoproteus from avian blood. J Parasitol. 2009;90:797-802.

54. White GC, Burnham KP. Program MARK: survival estimation from populations of marked animals. Bird Study. 1999;46:S120-39.

55. Eads DA, Biggins DE, Antolin MF, Long DH, Huyvaert KP, Gage KL. Prevalence of the generalist flea Pulex simulans on black-tailed prairie dogs (Cynomys ludovicianus) in New Mexico, USA: the importance of considering imperfect detection. J Wild Dis. 2015;51:498-502.

56. MacKenzie D, Nichols J, Royle J, Pollock K, Bailey L, Hines J. Occupancy modeling and estimation. San Diego, CA: Academic; 2006.

57. Burnham KP, Anderson DR. Model selection and multimodel inference: a practical information-theoretic approach. New York: Springer; 2002.

58. Barbieri MM, Berger JO. Optimal predictive model selection. Ann Stat. 2004:2:870-97.

59. Marzal A, Ricklefs RE, Valkiūnas G, AlbayrakT, Arriero E, Bonneaud C, et al. Diversity, loss, and gain of malaria parasites in a globally invasive bird. PLoS ONE. 2011;6:e21905.

60. Hellgren $\mathrm{O}$, Križanauskiene A, Valkiūnas G, Bensch S. Diversity and phylogeny of mitochondrial cytochrome $B$ lineages from six morphospecies of avian Haemoproteus (Haemosporida: Haemoproteidae). J Parasitol. 2007;93:889-97.

61. Hellgren O, Waldenström J, Perez-tris J, Szoll E, Si O, Hasselquist D, et al. Detecting shifts of transmission areas in avian blood parasites - a phylogenetic approach. Mol Ecol. 2007;16:1281-90.

62. Oakgrove KS, Harrigan RJ, Loiseau C, Guers S, Seppi B, Sehgal RN. Distribution, diversity and drivers of blood-borne parasite co-infections in Alaskan bird populations. Int J Parasitol. 2014:44:717-27.

63. Walther EL, Carlson JS, Cornel A, Morris BK, Sehgal RN. First molecular study of prevalence and diversity of avian haemosporidia in a Central California songbird community. J Ornithol. 2016;157:549-64.

64. Bensch S, Waldenström J, Jonzén N, Westerdahl H, Hansson B, Sejberg D, et al. Temporal dynamics and diversity of avian malaria parasites in a single host species. J Anim Ecol. 2007;76:112-22.

65. Podmokła E, Dubiec A, Drobniak SM, Arct A, Gustafsson L, Cichoń M. Determinants of prevalence and intensity of infection with malaria parasites in the blue tit. J Ornithol. 2014;155:721-7. 
66. Atkinson CT, Samuel MD. Avian malaria Plasmodium relictum in native Hawaiian forest birds: epizootiology and demographic impacts on apapane Himatione sanguinea. J Avian Biol. 2010;41:357-66.

67. Hatchwell BJ, Wood MJ, Anwar MA, Chamberlain DE, Perrins CM. The haematozoan parasites of common blackbirds Turdus merula: associations with host condition. Ibis. 2001;143:420-6.

68. Deviche P, McGraw K, Greiner EC. Interspecific differences in hematozoan infection in Sonoran desert Amophila sparrows. J Wildl Dis. 2005;41:532-41.

69. Garvin MC, Szell CC, Moore FR. Blood parasites of nearctic-neotropical migrant passerine birds during spring trans-gulf migration: impact on host body condition. J Parasitol. 2006;92:990-6.

70. Calero-Riestra M, Garcia JT. Sex-dependent differences in avian malaria prevalence and consequences of infections on nestling growth and adult condition in the tawny pipit Anthus campestris. Malaria J. 2016. https://doi. org/10.1186/s129360161220.

71. McCurdy DG, Shutler D, Mullie A, Forbes MR. Sex-biased parasitism of avian hosts: relations to blood parasite taxon and mating system. Oikos. 1998;303-12.

72. Møller AP, Christe P, Lux E. Parasitism, host immune function, and sexual selection. Q Rev Biol. 1991;74:3-20

73. Loye JE, Zuk M. Bird-parasite interactions: ecology, evolution, and behaviour. Oxford University Press, New York; Ornithology series, 2; 1991

74. Zuk M. Disease, endocrine-immune interactions, and sexual selection. Ecol. 1996;77:1037-42.

75. Zuk M, McKean KA. Sex differences in parasite infections: patterns and processes.Parasitol Int. 1996;26:1009-23.

76. Hughes $V$, Randolph S. Testosterone increases the transmission potential of tick-borne parasites. Parasitol. 2001;123:365-71.

77. Dawson RD, Bortolotti GR. Effects of hematozoan parasites on condition and return rates of American kestrels. Auk. 2000;117:373-80.

78. Ots I, Murumägi A, Horak P. Haematological health state indices of reproducing great tits: methodology and sources of natural variation. Funct Ecol. 1998:12:700-7.

79. Schultz A, Underhill LG, Earlé RA, Underhill G. Infection prevalence and absence of positive correlation between avian haemosporidian parasites, mass and body condition in the cape weaver Ploceus capensis. Ostrich. 2010;81:69-76.

80. Sanchez CA, Becker DJ, Teitelbaum CS, Barriga P, Brown LM, Majewska AA, et al. On the relationship between body condition and parasite infection in wild life: a review and meta-analysis. Ecol Lett. 2018:21:1869-84.
81. Khan R, Fallis A. Relapses in birds infected with species of Leucocytozoon. Can J Zool. 1970;48:451-5.

82. Applegate J. Spring relapse of Plasmodium relictum infections in an experimental field population of English sparrows (Passer domesticus). J Wildl Dis. 1971;7:37-42.

83. Ishtiaq F, Rao M, Huang X, Bensch S. Estimating prevalence of avian haemosporidians in natural populations: a comparative study on screening protocols. Parasit Vectors. 2017;10:127.

84. Svensson-Coelho M, Silva GT, Santos SS, Miranda LS, Araújo-Silva L, Ricklefs $\mathrm{R}$, et al. Lower detection probability of avian Plasmodium in blood compared to other tissues. J Parasitol. 2016;102:559-62.

85. Hammers M, Komdeur J, Kingma SA, Hutchings K, Fairfield EA, Gilroy DL, Richardson DS. Age-specific haemosporidian infection dynamics and survival in Seychelles warblers. Sci Rep. 2016;6:1-9.

86. Bichet C, Sorci G, Robert A, Julliard R, Lendvai AZ, Chastel O, Garnier S, Loisaeu C. Epidemiology of Plasmodium relictum infection in the house sparrow. J Parasitol. 2014;100:59-65.

87. Gonzalez G, Sorci G, Møller AP, Haussy C, De Lope F. Immunocompetence and condition-dependent sexual advertisement in male house sparrows (Passer domesticus). J Anim Ecol. 1999:68:1225-34.

88. Gonzalez G, Sorci G, Møller AP, Haussy C, De Lope F. Immunocompetence and condition-dependent sexual advertisement in male house sparrows (Passer domesticus). J Anim Ecol. 1999;68:1225-34.

89. Roulin A. Condition-dependence, pleiotropy and the handicap principle of sexual selection in melanin-based colouration. Biol Rev. 2016;91:328-48.

90. Owen JC, Moore FR. Swainson's thrushes in migratory disposition exhibit reduced immune function. J Ethol. 2008;26:383-8.

91. Beveroth TA, Ward MP, Lampman RL, Ringia AM, Novak RJ. Changes in seroprevalence of West Nile virus across Illinois in free-ranging birds from 2001 through 2004. Am J Trop Med Hyg. 2006;74:174-9.

92. Hellgren O, Waldenström J, Bensch S. A new PCR assay for simultaneous studies of Leucocytozoon, Plasmodium, and Haemoproteus from avian blood. J Parisitol. 2004;90:797-802.

\section{Publisher's Note}

Springer Nature remains neutral with regard to jurisdictional claims in published maps and institutional affiliations.
Ready to submit your research? Choose BMC and benefit from:

- fast, convenient online submission

- thorough peer review by experienced researchers in your field

- rapid publication on acceptance

- support for research data, including large and complex data types

- gold Open Access which fosters wider collaboration and increased citations

- maximum visibility for your research: over 100M website views per year

At BMC, research is always in progress.

Learn more biomedcentral.com/submissions 